\title{
ПАРАМЕТРИЧЕСКИЙ АНАЛИЗ СХЕМЫ ПАРОГАЗОВОЙ УСТАНОВКИ С КОМБИНАЦИЕЙ ТРЕХ ЦИКЛОВ ДЛЯ ПОВЫШЕНИЯ КПД ПРИ РАБОТЕ В СЕВЕРНЫХ ГАЗОДОБЫВАЮЩИХ РАЙОНАХ
}

\section{Галашов Николай Никитович',}

gal@tpu.ru

\author{
Цибульский Святослав Анатольевич', \\ stzibulsky@tpu.ru
' Национальный исследовательский Томский политехнический университет, Россия, 634050, г. Томск, пр. Ленина, 30.

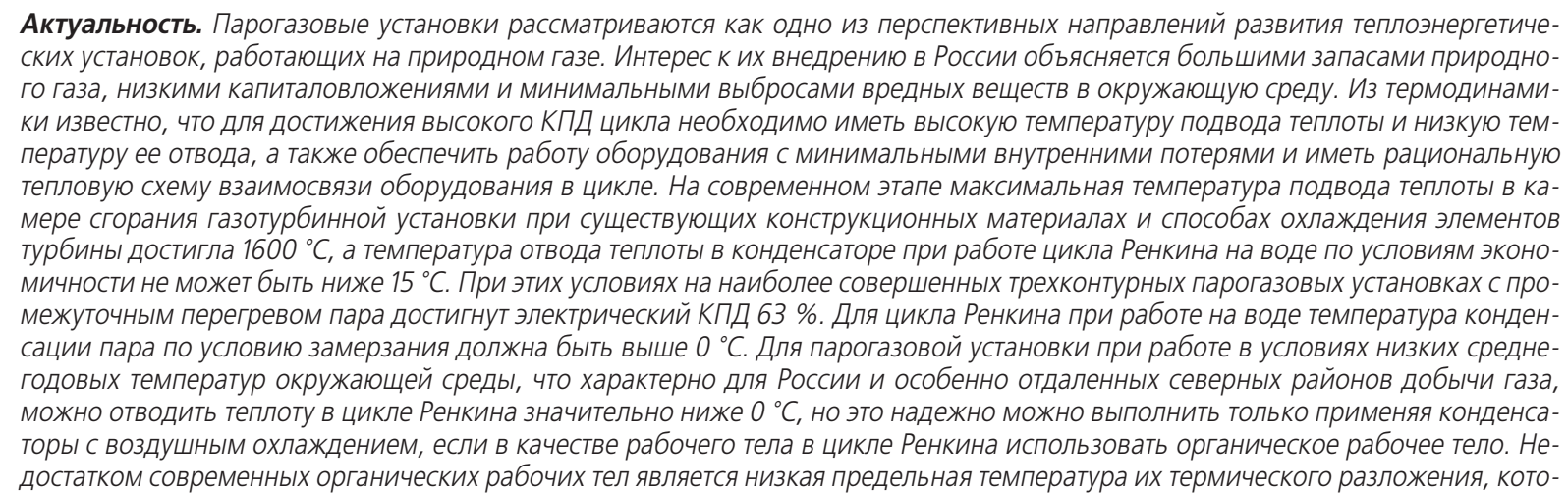
рая составляет $300 . . .400^{\circ} \mathrm{C}$.

Объект: парогазовые установки с циклами на трех рабочих телах, где верхний цикл Брайтона работает на продуктах сгорания природного газа, средний - цикл Ренкина - работает на воде и водяном паре в интервале температур 100...650 ${ }^{\circ} \mathrm{C}$, а нижний Органический цикл Ренкина - работает на органических рабочих телах в интервале температур -30...250 ${ }^{\circ} \mathrm{C}$.

Цель: выбор рациональной технологической схемы парогазовой установки с применением циклов на трех рабочих телах и воздушного конденсатора для возможности надежного отвода теплоты от органического рабочего тела при температуре ниже $0{ }^{\circ} \mathrm{C}$ и определение оптимальных параметров циклов.

Методы. Сложные теплоэнергетические системы, включая парогазовые установки, характеризуются многообразием процессов, протекающих в их элементах. Такие установки можно эффективно исследовать только с помощью методов математического моделирования и оптимизации. При проведении исследований в данной работе использован системный подход, методы энергетических балансов и расчет термодинамических и теплофизических параметров рабочих тел с помощью современных сертифицированных программ.

Результаты. Разработана оригинальная схема парогазовой установки утилизационного типа с циклами на трех рабочих телах, где верхний цикл Брайтона работает на продуктах сгорания природного газа, средний цикл Ренкина работает на воде и водяном паре, нижний - Органический цикл Ренкина - работает на органическом рабочем теле с конденсацией его в воздушном конденсаторе. Разработана математическая модель и программа расчета предложенной схемы. Определено наиболее эффективное органическое рабочее тело для нижнего цикла Ренкина. Проведен параметрический анализ влияния основных параметров циклов на КПД брутто и нетто парогазовой установки.

\section{Ключевые слова:}

Парогазовая установка, органическое рабочее тело, Органический цикл Ренкина, воздушный конденсатор, математическое моделирование.

\section{Введение}

На современном этапе развития электроэнергетики России до 70 \% электроэнергии производится на основе сжигания природного газа, при этом наиболее совершенными электрогенерирующими установками являются парогазовые установки (ПГУ) утилизационного типа с котлом-утилизатором $[1,2]$. За счет низких капитальных затрат, высокого КПД, низких выбросов вредных веществ в окружающую среду, небольшого потребления воды для технологического процесса ПГУ позволяют решить большой ряд экономических и экологических проблем в энергетике [3]. ПГУ являются ком- бинацией двух энергетических установок: газотурбинной (ГТУ) и паротурбинной (ПТУ). При этом главную роль играет ГТУ, так как в ПГУ утилизационного типа на ней вырабатывается до $2 / 3$ мощности, а для получения высоких КПД необходимо иметь высокую температуру газов перед турбиной. Современные мощные энергетические ГТУ фирм General Electric, Siemens, Mitsubishi при температуре перед газовой турбиной $1500-1600{ }^{\circ} \mathrm{C}$ имеют КПД выше $40 \%$ [4].

КПД ПТУ зависит от тепловой схемы (одно, двух или трехконтурная), от температуры пара перед паровой турбиной, а также от температуры от- 
вода тепла в конденсаторе. Для современных мощных ГТУ температура уходящих газов достигла $600 \ldots 640$ 둔 что позволяет иметь температуру пара перед паровой турбиной $560 \ldots 600{ }^{\circ} \mathrm{C}$. Увеличение этой температуры связано с существенным удорожанием ГТУ и ПТУ и снижением их надежности и маневренности. Температура отвода тепла в конденсаторе при работе ПТУ на водяном паре ограничена температурой замерзания воды $-0{ }^{\circ} \mathrm{C}$, а из-за экономических условий она обычно не ниже $20{ }^{\circ} \mathrm{C}$. В Северных районах России, где в зимнее время температура воздуха до 8 месяцев ниже $0 . . .-20{ }^{\circ} \mathrm{C}$, можно уменьшить температуру отвода тепла в цикле Ренкина, если вместо охлаждаемых водой применять конденсаторы с воздушным охлаждением, а в качестве рабочего тела - органические вещества, не замерзающие при температурах ниже $0{ }^{\circ} \mathrm{C}$, которые применяются в органическом цикле Ренкина (ОЦР). Но органические рабочие тела (ОРТ) разрушаются при температурах выше $300 \ldots 400{ }^{\circ} \mathrm{C}$. Поэтому предложена ПГУ на основе трех циклов: верхний - газотурбинный цикл Брайтона, средний - одноконтурный паротурбинный цикл $\mathrm{PeH}^{-}$ кина, и нижний - ОЦР. Применение ОРТ, не замерзающих при температурах до $-50{ }^{\circ} \mathrm{C}$, позволяет повысить КПД цикла, надежность работы воздушного конденсатора, а также уменьшить габариты турбины и конденсатора.

Применяемые в ПГУ на современном этапе ГТУ, работающие на основе цикла Брайтона, и ПТУ - на основе пароводяного цикла Ренкина хорошо описаны в $[1,2]$. Большой интерес представляет применение ОЦР при совместной работе в комплексе с циклами Брайтона и Ренкина на водяном паре.

Опубликовано большое число работ по оптимизации параметров ОЦР и выбору рабочих тел для него [5-10]. В настоящее время имеется большой список рабочих тел для применения в ОЦР и выбор из них наилучшего для данных условий применения цикла является актуальной задачей.

В [11-14] предложено применять двойные циклы Ренкина, что позволяет оптимизировать параметры и использовать разные рабочие тела. Так, в [11] предлагается применять r1234yf, r1234ze, пентан, бутан, толуол, циклогексан, циклопентан. Показано, что при правильном выборе рабочих тел рост эффективности может составить около $33 \%$. В [12] приведен термоэкономический анализ газовой турбины и парогазовой установки с двумя турбинами на $\mathrm{CO}_{2}$ и промежуточным масляным контуром. Необходимо отметить, что в этой установке конденсация $\mathrm{CO}_{2}$ возможна только в нижнем цикле, а для передачи теплоты от верхнего цикла к нижнему необходим газо-газовый теплообменник с низким коэффициентом теплопередачи больших размеров. В [13] рассмотрена установка при работе двух турбин на R124, R134a, R245fa, R600, R600a и R1234yf, при этом наилучшие результаты получены при работе на R245fa и R600.
В [14] проведен термоэкономический анализ и многоцелевая оптимизация комбинированного цикла с турбинами: газовой, паровой и на органическом рабочем теле. Недостатком этого цикла на трех рабочих телах является то, что паровая турбина и турбина органического цикла Ренкина имеют конденсаторы, из которых теплота конденсации отводится в окружающую среду. Также недостатком является то, что в ОЦР применен конденсатор с водяным охлаждением, температура конденсации в котором не может быть ниже $15^{\circ} \mathrm{C}$. Как показано в $[15,16]$, более экономичной является схема, когда в цикле паровой турбины нет конденсатора, а конденсация пара происходит в испарителе ОРТ и вся теплота конденсации пара передается рабочему телу нижнего цикла, в этом случае паровой цикл Ренкина не имеет внешней потери теплоты. А отвод теплоты в окружающую среду в значительно меньшем количестве есть только в конденсаторе ОЦР, особенно, если применить конденсатор с воздушным охлаждением, отводить из него теплоту можно при температурах конденсации значительно ниже $0{ }^{\circ} \mathrm{C}$.

В работе [17] рассмотрена тепловая схема ПГУ тройного цикла с современной мощной ГТУ и паровым и органическим циклом Ренкина. Показано, что при низких температурах наружного воздуха можно получить КПД нетто до $63 \%$. K недостаткам этой схемы следует отнести применение промежуточного перегрева в паровом цикле, так как он уменьшает расход пара на турбину, из-за уменьшения теплоты, идущей на парообразование, а также усложняется схема ПГУ и снижается маневренность установки.

В [18] рассмотрена более простая схема ПГУ с одноконтурным пароводяным и органическим циклом Ренкина с воздушным конденсатором. Показано, что КПД этой схемы существенно зависит от выбора рабочего тела. Наибольший КПД получен для пентана. Недостатком этой схемы является то, что при высокой температуре рабочего тела на входе в котел-утилизатор будет высокой температура уходящих газов, в результате чего не будет полностью использован тепловой потенциал уходящих газов.

Из проведенного анализа следует, что для получения высоких КПД актуальны вопросы по выбору оптимальной схемы ПГУ с полным использованием теплоты уходящих газов в котле-утилизаторе и минимальными потерями тепла в конденсаторе, а также выбор наиболее эффективных рабочих тел для циклов ПТУ.

Целью настоящей работы является выбор рациональной технологической схемы ПГУ с применением циклов на трех рабочих телах и воздушного конденсатора для возможности надежного отвода теплоты от органического рабочего тела при температуре ниже $0{ }^{\circ} \mathrm{C}$, а также выбор ОРТ для ОЦР и определение оптимальных параметров циклов ПТУ при работе на водяном паре и ОРТ. 


\section{Схема и циклы работы парогазовой установки}

Для исследований ПГУ с тремя циклами была разработана оригинальная схема (рис. 1), в которой обеспечивается низкая температура уходящих газов в котле-утилизаторе и низкая температура отвода теплоты в конденсаторе с воздушным охлаждением.

На рис. 2 в TS-диаграмме приведены процессы, протекающие в оборудовании схемы ПГУ. На рис. 2, $а$ показаны процессы всех циклов, а на рис. 2, б представлены процессы в ОЦР, которые сложно понять на рис. $2, a$.

ПГУ работает следующим образом. В верхнем цикле Брайтона в компрессоре ВК атмосферный воздух в адиабатном процессе 1-2 сжимается до давления в камере сгорания КС, при этом увеличивается его температура. В камеру сгорания дожимными компрессорами (не показаны на схеме) подается топливо, в результате его горения в изобарном процессе 2-3 подводится теплота и обеспечивается высокая температура продуктов сгорания топлива $\mathrm{T}_{3}$ перед газовой турбиной (ТГ). В газовой турбине в адиабатном процессе 3-4 продукты сгорания со- вершают работу и с температурой $\mathrm{T}_{4}$ поступают в котел-утилизатор (КУ), в котором проходят через пароперегреватель (ПП), испаритель (И), экономайзер (ЭК) и газовый подогреватель (ГПОРТ), после чего с температурой уходящих газов $\mathrm{T}_{\mathrm{yx}}=\mathrm{T}_{27}$ отводятся в дымовую трубу. В результате передачи теплоты в КУ температура дымовых газов в изобарном процессе снижается до состояний за ПП 24 , за И 25, за ЭК 26 и за ГПОРТ 27.

В среднем цикле Ренкина конденсат пара из испарителя (ИОРТ) сжимается в адиабатном процессе 7-8 питательным насосом (НПВ) и подает в экономайзер (ЭК), где в изобарном процессе 8-9 нагревается до температуры на $8 . .10 \mathrm{~K}$ ниже, чем температура насыщения при давлении в барабане (Б), и идет в барабан. В испарителе (И) образуется пароводяная смесь, которая поступает в барабан (Б), а из него насыщенный пар идет в пароперегреватель (ПП), где в изобарном процессе 12-5 перегревается и поступает в турбину (ТП), в которой в адиабатном процессе 5-6 совершает работу и уходит в испаритель (ИОРТ), где в изобарном процессе 6-7 конденсируется и передает тепло ОРТ.

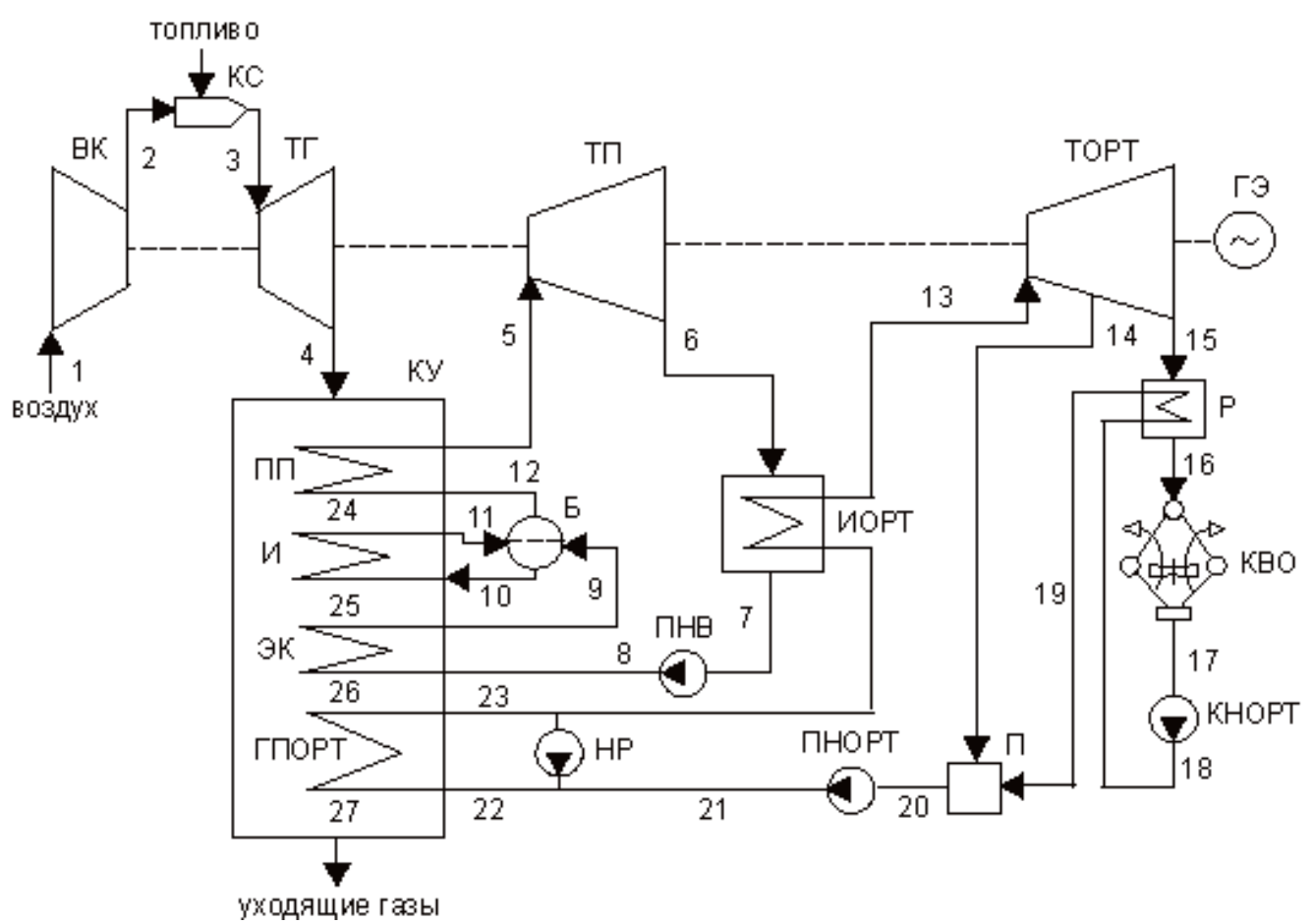

Рис. 1. Приниипиальная тепловая схела ПГУ: $K$ - колпрессор, $К С$ - камера сгорания, ТГ - турбина газовая, КУ - котел-утилизатор, ТП - турбина паровая, ТОРТ - турбина ОРТ, ПП - пароперегреватель, И - испаритель, Б - барабан, ЭК - экономайзер, ГПОРТ - газовый подогреватель конденсата ОРТ, ИОРТ - испаритель ОРТ, ПНВ - питательный насос воды, Р - рекуператор ОРТ, КВО - конденсатор воздушного охлаждения, КНОРТ - конденсатный насос ОРТ, ГЭ - генератор электрического тока, НР - насос рециркуляции ОРТ, ПНОРТ - питательный насос ОРТ, П - регенеративньй подогреватель ОРТ

Fig. 1. Cycle diagram of combine cycle gas turbine (CCGT): $K(C)$ - compressor, $K C$ (CC) - combustion chamber, TI (GT) - gas turbine, KY (HRSG) - heat recovery steam generator, TП (HPST) - high pressure steam turbine, TOPT (LPST) - low pressure steam turbine, $\Pi \Pi(S H)$ - superheater, $И(E V)$ - evaporator, $Б(D)$-drum, ЭK (EC) - economizer, ГПOPT (GH OWF) - gas heater organic working fluid, ИОРТ (EV OWF) - evaporator organic working fluid, ПНВ (WFP) - water feed pump, $P$ ( $R$ OWF) - recuperator organic working fluid, KBO (AC) - air condenser, KHOPT (CP OWF) - condensate pump organic working fluid, $\Gamma \ni$ (EG) - electric generator, HP (RP OWF) - recirculation pump organic working fluid, ПHOPT (FP OWF) - feed pump organic working fluid, $\Pi$ (RH OWF) - regenerative heater organic working fluid 

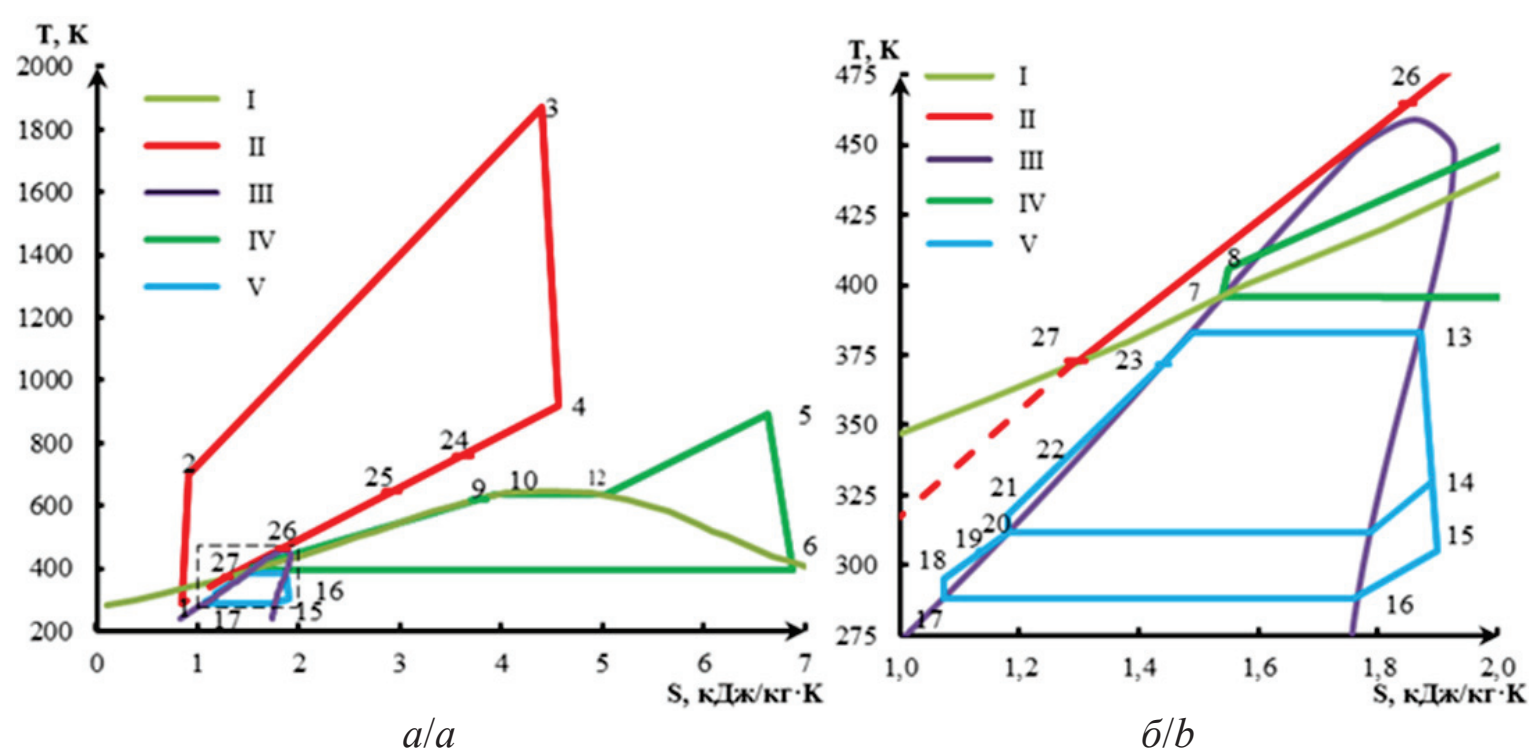

Рис. 2. Цциллы ПГУ в ТS-диаграмме: а) циклы ПГУ; б) ОЦР; числами обозначены точки, представленные на рис. 1; I - линии насыщения для воды и водяного пара, II - иикл ГТУ и отвода тепла от уходящих газов в КУ, III - линии насыщения для R365mfc, IVиикл Ренкина на водяном паре, $V$-ОЦР

Fig. 2. TS-diagram of CCGT cycles: a) cycles of CCGT; b) cycle of Organic Rankine cycle (ORC); the numbers denote the points shown in Fig. 1; I - saturation line for water and water steam, II - Gas turbine unit (GTU) cycle and heat removal from flue gases in heat recovery steam generator (HRSG), III - saturation line of R365mfc, IV - Rankine cycle on water steam, $V-O R C$

В нижнем цикле (ОЦР) в испарителе (ИОРТ) в изобарном процессе 23-13 испаряется органическое рабочее тело при температуре насыщения, которая на $8 \ldots 12{ }^{\circ} \mathrm{C}$ ниже температуры конденсации пара, и идет в турбину ТОРТ, где в адиабатном процессе 13-14-15 совершает работу и через рекуператор (Р) уходит в конденсатор воздушного охлаждения (КВО), в котором в изобарном процессе 16-17 конденсируется. Температура конденсации принимается на $10 . .15{ }^{\circ} \mathrm{C}$ выше температуры охлаждающего воздуха. Из конденсатора конденсат ОРТ насосом (КНОРТ) через рекуператор (Р) подается в ГПОРТ. В рекуператоре (Р) конденсат ОРТ подогревается в изобарном процессе 18-19 при охлаждении пара ОРТ в изобарном процессе 15-16. По нормам работы котлов-утилизаторов для предотвращения низкотемпературной коррозии рабочее тело перед подачей в котел должно иметь температуру не ниже $60{ }^{\circ} \mathrm{C}$. В данной схеме для подогрева ОРТ перед ГПОРТ возможны два способа либо с помощью насоса рециркуляции (НР), либо подогревом в смешивающем подогревателе (П) паром из отбора 14 турбины ТОРТ. Подача конденсата ОРТ из подогревателя (П) в газовый подогреватель (ГПОРТ) производится питательным насосом (ПНОРТ) в адиабатном процессе 20-21. Мощность турбин ТГ, ТП, ТОРТ по общему валу передается в электрический генератор (ГЭ).

\section{Математическая модель}

Модель расчета схемы ПГУ представляет систему уравнений, характеризующих: процессы в оборудовании газотурбинной установки, в паровой и
OPТ турбине, в компрессоре и насосах, а также уравнения материальных и энергетических балансов в теплообменном оборудовании.

Та как ряд рабочих тел (воздух, дымовые газы) представляют смеси различных веществ, чтобы упростить анализ были сделаны следующие допущения:

- оборудование работает в стационарном режиме;

- предполагается, что воздух и дымовые газы являются идеальными газовыми смесями;

- предполагается, что воздух состоит из $79 \%$ $\mathrm{N}_{2}$ и $21 \% \mathrm{O}_{2}$;

- дымовые газы состоят из смеси воздуха, $\mathrm{CO}_{2}$ и $\mathrm{H}_{2} \mathrm{O}$

- топливом является природный газ, состоящий в основном из метана;

- давление окружающей среды $p_{1}=0,1013$ МПа;

- температура окружающей среды может меняться от -35 до $35^{\circ} \mathrm{C}$;

- температура воздуха на входе воздушного компрессора ГТУ поддерживается постоянной, $T_{1}=15^{\circ} \mathrm{C}$.

Термодинамические и теплофизические параметры воздуха, продуктов сгорания топлива, воды, водяного пара и ОРТ определяются по функциям библиотеки «REFPROP» [19].

\section{1. Модель цикла Брайтона}

Температура на выходе компрессора

$$
T_{2}=T_{1}\left(1+1 / \eta_{k}\left(\varepsilon^{m}-1\right)\right),
$$

где $\eta_{\mathrm{k}}=0,92$ - изоэнтропийный КПД компрессора; $\varepsilon=p_{2} / p_{1}$ - степень повышения давления в компресcope; $m=(k-1) / k$, где $k$ - коэффициент адиабаты воздуха. 
Эффективная мощность, подведенная от вала к воздуху в компрессоре, $\mathrm{\kappa}$ В

$$
N_{\mathrm{r}}=G_{\mathrm{B}}\left(h_{2}-h_{1}\right) / \eta_{\mathrm{M}},
$$

где $G_{\text {в }}$ - расход воздуха, кг/c; $h_{1}, h_{2}$ - энтальпии воздуха на входе и выходе компрессора, определяются по давлениям и температурам в соответствующих точка цикла, кДж/кг; $\eta_{\mathrm{m}}=0,98$ - механический КПД компрессора.

Тепловой баланс камеры сгорания

$$
\left(G_{\mathrm{B}} h_{2}+B Q_{\mathrm{H}}\right) \eta_{\mathrm{kC}}=G_{\mathrm{r}} h_{3},
$$

где $B$ - расход топлива, кг/с; $Q_{\text {н }}$ низшая теплота сгорания, кДж/кг; $\eta_{\text {кс }}-$ КПД камеры сгорания; $G_{\mathrm{r}}=G_{\mathrm{B}}+B-$ расход дымовых газов; $h_{3}-$ энтальпия газов на выходе $\mathrm{KC}$, определяется по давлению $p_{3}$ и температуре $T_{3}$ (задается), где $p_{3}=p_{2}-\Delta p_{\mathrm{KC}}$, где $\Delta p_{\mathrm{KC}}=0,05 p_{2}-$ потери давления в КС.

Тепловая мощность, подведенная при сжигании топлива в КС, кВт: $Q_{\mathrm{Kc}}=B Q_{\text {н }}$.

Температура газов на выходе газовой турбины

$$
T_{4}=T_{3}\left(1-1 / \eta_{\text {ГТ }}\left(\varepsilon_{1}^{m 1}-1\right)\right),
$$

где $\eta_{\text {гт }}=0,9$ - изоэнтропийный КПД газовой турбины; $\varepsilon_{1}=p_{3} / p_{4}$ - степень повышения давления в газовой турбине, где $p_{4}=p_{1}+\Delta p_{\text {ку }}$, где $\Delta p_{\mathrm{Ky}}=0,05 p_{1}-$ потери давления в котле-утилизаторе; $m_{1}=\left(k_{1}-1\right) / k_{1}$, где $k_{1}$ - коэффициент адиабаты продуктов сгорания топлива с воздухом.

Эффективная мощность газовой турбины, кВт

$$
N_{\text {Гт }}=G_{\mathrm{r}}\left(h_{3}-h_{4}\right) \eta_{\mathrm{M}},
$$

где $h_{4}$ - энтальпия газов на выходе газовой турбины, определяется по давлению $p_{4}$ и температуре $T_{4}$; $\eta_{\mathrm{м}}$ - механический КПД.

Эффективная мощность цикла ГТУ, кВт

$$
N_{\text {гту }}=N_{\text {гт }}-N_{\text {к }} \text {. }
$$

\section{2. Модель парового цикла Ренкина}

Расход пара, поступающего в паровую турбину, определяется на основе решения уравнения теплового баланса системы ПП-И в КУ (рис. 1)

$$
D_{\text {пI }}\left(h_{5}-h_{9}\right)=G_{\text {г }}\left(h_{4}-h_{25}\right),
$$

где $h_{5}$ - энтальпия пара на выходе ПП, определяется по давлению $p_{5}$, которое задается, и по температуре $\mathrm{T}_{5}$, которая определяется как $T_{5}=T_{4}-\theta_{5}$, где $\theta_{5}$ принимается $20 . . .40 \mathrm{~K}$; для определения энтальпий $h_{9}$ и $h_{25}$ необходимо определить давление в барабане как $p_{5}=1,2 p_{5}$, по нему определить температуру насыщения в барабане $T_{s \mathrm{~B}}$. Температура воды на входе в барабан $T_{9}=T_{s \bar{b}}-\theta_{\ni}$, где $\theta_{\ni}=5 \mathrm{~K}$, а температура газа за $И \mathrm{~T}_{25}=\mathrm{T}_{s \mathrm{5}}+\theta_{\mathrm{И}}$, где $\theta_{\mathrm{U}}=10$ К. Энтальпия $h_{9}$ определяется по $T_{9}$ и $p_{\mathrm{5}}$, а $h_{25}$ по $T_{25}$ и $p_{4}$. По $T_{s \mathrm{~B}}$ определяются энтальпия кипящей воды $h_{10}$ и энтальпия сухого насыщенного пара $h_{12}$.

Энтальпия дымовых газов в точке $24 h_{24}$ определяется из уравнения теплового баланса ПП

$$
D_{\text {пI }}\left(h_{5}-h_{12}\right)=G_{\mathrm{r}}\left(h_{4}-h_{24}\right) \text {. }
$$

Энтальпия пароводяной смеси в точке $11 h_{11}$ определяется из уравнения теплового баланса $И$

$$
D_{\text {пा }}\left(h_{11}-h_{10}\right)=G_{\text {г }}\left(h_{24}-h_{25}\right) \text {. }
$$

Энтальпия пара на выходе паровой турбины $h_{6}$ определяется по давлению за турбиной $p_{6}$, которое задается, и процессу расширения в турбине, для этого определяется энтропия $s_{5}$ по $T_{5}$ и $p_{5}$, а по $s_{5}$ и $p_{6}$ определяется энтальпия в конце изоэнтропийного процесса расширения в турбине $h_{6 s}$. Энтальпия $h_{6}=h_{5}-\left(h_{5}-h_{6 s}\right) \eta_{\text {тп }}$, где $\eta_{\text {тп }}-$ внутренний относительный КПД паровой турбины. Энтальпия кипящей воды на выходе ИОРТ $h_{7}$ определяется по давлению $p_{6}$. Энтальпия воды за ПНВ $h_{8}=h_{7}+\Delta h_{\text {Пнв }}$, где повышение энтальпии в ПНВ $\Delta h_{\text {Пнв }}=\left(1,3 p_{\text {Б }}-p_{6}\right) \nu_{\text {н }} / \eta_{\text {н }}$, где $v_{\text {н }}$ - удельный объем воды в насосе; $\eta_{\text {н }}=0,8-$ КПД насоса.

Энтальпия дымовых газов за ЭК $h_{26}$ определяется из теплового баланса

$$
D_{\text {пI }}\left(h_{9}-h_{8}\right)=G_{\text {г }}\left(h_{25}-h_{26}\right) .
$$

Эффективная мощность паровой турбины, кВт

$$
N_{\mathrm{TI}}=D_{\text {II }}\left(h_{5}-h_{6}\right) \eta_{\mathrm{M}} \text {. }
$$

\section{3. Модель органического цикла Ренкина}

Расход пара, поступающего в турбину ТОРТ, определяется на основе решения уравнения теплового баланса ИОРТ (рис. 1)

$$
D_{\text {ОРТ }}\left(h_{13}-h_{23}\right)=D_{\text {п }}\left(h_{6}-h_{7}\right) \eta_{\text {иорт }},
$$

где $h_{13}$ - энтальпия сухого насыщенного пара OPT на выходе ИОРТ, определяется по температуре $T_{13}$, которая определяется как $T_{13}=T_{7}-\theta_{\text {иорт }}$, где $\theta_{\text {иорт }}$ принимается $10 \mathrm{~K}$; энтальпия $h_{23}$ определяется из теплового баланса ГПОРТ

$$
\left(D_{\mathrm{OPT}}+D_{\mathrm{P}}\right)\left(h_{23}-h_{22}\right)=G_{\mathrm{r}}\left(h_{26}-h_{27}\right) \text {, }
$$

где $D_{\mathrm{P}}$ - расход ОРТ через НР при подогреве ОРТ перед ГПОРТ путем рециркуляции, при подогреве OРТ в $\Pi D_{\mathrm{P}}=0 ; h_{22}$ - энтальпия ОРТ на входе в ГПОРТ, определяется по заданной температуре 60 ${ }^{\circ} \mathrm{C}$ и давлению $p_{21}$ за ПНОРТ, которое определяется как $1,3 p_{13}$; давление $p_{13}$ определяется как давление насыщения по температуре $\mathrm{T}_{13}$; энтальпия $h_{27}$ определяется по давлению $p_{4}$ и температуре уходящих дымовых газов, которая принимается $100 . .120{ }^{\circ} \mathrm{C}$.

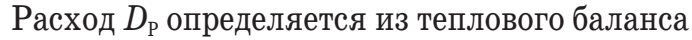

$$
\left(D_{\text {OPT }}+D_{\mathrm{P}}\right) h_{22}=D_{\mathrm{P}} h_{23}+D_{\mathrm{OPT}} h_{21} \text {, }
$$

где $h_{21}=h_{20}+\Delta h_{\text {ПнорТ }}, \Delta h_{\text {ПноРТ }}=\left(p_{21}-p_{20}\right) v_{\mathrm{H}} / \eta_{\mathrm{H}}$,

Давление в КВО $p_{16}=p_{17}$ определяется по температуре насыщения в конденсаторе $T_{\mathrm{r}}$, которая принимается на $10 . .15 \mathrm{~K}$ выше температуры охлаждающего воздуха. Температура пара ОРТ за P $T_{16}=T_{\text {к }}+5$ К. По $T_{16}$ и $p_{16}$ определяется $h_{16}$.

Энтальпия кипящей жидкости ОРТ $h_{17}$ определяется по $T_{\mathrm{r}}$. Энтальпия $h_{18}=h_{17}+\Delta h_{\text {кнорт }}$, $\Delta h_{\mathrm{kнорт}}=\left(p_{18}-p_{17}\right) v_{\mathrm{H}} / \eta_{\text {н }}$, где $p_{18}=1,3 p_{20}$. Давление за TOPT $p_{15}=1,1 p_{16}$. Давление в отборе ТОРТ $p_{14}=1,05 p_{20}$.

Энтальпия пара на выходе турбины ТОРТ $h_{15}$ определяется по давлению за турбиной $p_{15}$ и процессу расширения в турбине, для этого определяется энтропия $s_{13}$ по $T_{13}$ и $p_{13}$, а по $s_{13}$ и $p_{15}$ определяется энтальпия в конце изоэнтропийного процесса расширения в турбине $h_{15 s}$. Энтальпия $h_{15}=h_{13}-\left(h_{13}-h_{15 s}\right) \eta_{\text {торт }}$, где $\eta_{\text {торт }}=0,87$ - внутренний относительный КПД турбины ТОРТ. Энтальпия в отборе $h_{14}=h_{13}-\left(h_{13}-h_{14 s}\right) \eta_{\text {торт }}$, где $h_{14 s}$ определяется по $s_{13}$ и $p_{14}$. 
Энтальпия $h_{19}$ определяется из теплового баланса рекуператора

$$
\left(h_{19}-h_{18}\right)=\left(h_{15}-h_{16}\right) \eta_{\mathrm{P}}
$$

где $\eta_{\mathrm{P}}=0,99$ - КПД рекуператора.

Энтальпия $h_{20}=h_{19}$, если подогрев ОРТ перед ГПОРТ производится рециркуляцией, иначе $h_{20}$ определяется как кипящая жидкость по $p_{20}$.

Расход пара на подогреватель (П) $D_{14}$ определяется из уравнений материального и теплового баланса:

$$
\begin{gathered}
D_{14}+D_{\mathrm{\kappa}}=D_{\mathrm{OPT}} ; \\
\left(D_{14} h_{14}+D_{\mathrm{K}} h_{19}\right) \eta_{\Pi}=D_{\text {ОРТ }} h_{20},
\end{gathered}
$$

где $D_{\text {к }}$ - расход пара ОРТ в конденсатор; $\eta_{\Pi}=0,99-$ КПД подогревателя.

Эффективная мощность турбины ТОРТ без отбора (17а) и с отбором (17б), кВт

$$
\begin{gathered}
N_{\text {ТОРТ }}=D_{\text {ОРТ }}\left(h_{13}-h_{15}\right) \eta_{\mathrm{m}} \cdot \\
N_{\text {TОРТ }}=\left(D_{\mathrm{K}}\left(h_{13}-h_{15}\right)+D_{14}\left(h_{13}-h_{14}\right)\right) \eta_{\mathrm{M}} .
\end{gathered}
$$

Электрическая мощность ПГУ брутто, кВт

$$
N_{\text {бр }}=\left(N_{\text {TГ }}+N_{\text {Tा }}+N_{\text {TOРT }}\right) \eta_{\text {r }},
$$

где $\eta_{\mathrm{r}}=0,98-$ КПД ГЭ.

Электрический КПД ПГУ брутто

$$
\eta_{\text {бр }}=N_{\text {бр }} / Q_{\mathrm{Kc}} \text {. }
$$

Электрические мощности, затраченные на собственные нужды ПГУ, кВт:

- на питательный насос воды $N_{\text {пнв }}=D_{\text {п }} \Delta h_{\text {пнв }}$;

- на питательный насос ОРТ $N_{\text {пнорт }}=D_{\text {оРт }} \Delta h_{\text {Пнорт }}$;

- на конденсатный насос ОРТ $N_{\text {кнорт }}=D_{\mathrm{k}} \Delta h_{\text {кнорт }}$;

- на насос рециркуляции ОРТ $N_{\mathrm{HP}}=D_{\mathrm{P}} \Delta h_{\mathrm{HP}}$, где $\Delta h_{\mathrm{HP}}=\left(p_{21}-p_{23}\right) \nu_{\mathrm{H}} / \eta_{\mathrm{H}} ;$

- на вентиляторы КВО $N_{\text {кв0 }}=G_{\text {Кв } 0} \Delta h_{\text {Кв0 }}$, где $\Delta h_{\mathrm{KB} 0}=\Delta p_{\mathrm{B}} v_{\mathrm{B}} / \eta_{\mathrm{B}}, \Delta p_{\mathrm{B}}=30 \ldots 50 \kappa \Pi а ; G_{\mathrm{KB}}$ определяется из теплового баланса $G_{\text {кв }} C_{\mathrm{B}} \Delta T_{\mathrm{B}}=D_{\mathrm{k}}$ $\left(h_{16}-h_{17}\right)$, где $C_{\mathrm{B}}=1,006 \mathrm{\kappa Дж/кг} \mathrm{-} \mathrm{теплоемкость}$ воздуха; $\Delta T_{\text {в }}=10 . . .15 \mathrm{~K}$ - нагрев воздуха в $\mathrm{KBO}$;

- на дожимные компрессоры $N_{\text {дк }}=B \Delta h_{\text {дк }}$, где $\Delta h_{\text {дк }}=\left(p_{2}-p_{1}\right) v_{\text {пг }} / \eta_{\text {дк }}$, где $v_{\text {пг }}=1,27 \mathrm{M}^{3} / \kappa \Gamma-$ удельный объем природного газа; $\eta_{\text {дк }}=0,8-$ КПД ДК.

Суммарная электрическая мощность на собственные нужды ПГУ, $к \mathrm{~B}$ т

$$
N_{\text {СН }}=N_{\text {ПнВ }}+N_{\text {пноРТ }}+N_{\text {КНоРт }}+N_{\text {HР }}+N_{\text {Кво }}+N_{\text {дк }} \cdot
$$

Электрическая мощность ПГУ нетто, кВт

$$
N_{\text {нт }}=N_{\text {бр }}-N_{\text {СH }} \text {. }
$$

Электрический КПД ПГУ нетто

$$
\eta_{\mathrm{HT}}=N_{\mathrm{HT}} / Q_{\mathrm{KC}} \text {. }
$$

КПД котла-утилизатора определяется как

$$
\eta_{\text {ку }}=\left(h_{4}-h_{27}\right) /\left(h_{4}-h_{0 \mathrm{c}}\right),
$$

где $h_{\text {ос }}$ - энтальпия окружающей среды, определяется по температуре и давлению окружающего воздуха.

На основе уравнений (1)-(23) представленной модели разработана программа в MS Office Excel с подключенным модулем базы веществ REFPROP.

\section{Результаты расчета и их анализ}

Для цикла Брайтона была выбрана газотурбинная установка фирмы General Electric GE 9HA.02 [20], которая в номинальном режиме имеет элек- трическую мощность 571 МВт; КПД нетто 43,9 \%; степень повышения давления в компрессоре $\varepsilon=23,8$; температуру продуктов сгорания на входе в газовую турбину $T_{3}=1873 \mathrm{~K}$, а на выходе $T_{4}=918 \mathrm{~K}$; расход воздуха при температуре $T_{1}=288 \mathrm{~K}$ и относительной влажности $60 \% G_{\mathrm{B}}=938,4 \mathrm{\kappa г} / \mathrm{c}$, а расход продуктов сгорания $G_{\mathrm{r}}=964,5 \mathrm{\kappa г} / \mathrm{c}$.

В качестве топлива для ГТУ выбран природный газ следующего состава, \%: метан $\mathrm{CH}_{4}=93,9$; этан $\mathrm{C}_{2} \mathrm{H}_{6}=1,3$; пропан $\mathrm{C}_{3} \mathrm{H}_{8}=1,3$; бутан $\mathrm{C}_{4} \mathrm{H}_{10}=0,8$; оксид углерода $\mathrm{CO}=0,4$.

Для паротурбинного цикла Ренкина приняты следующие параметры: $\theta_{5}=25 \mathrm{~K}$; давление пара перед паровой турбиной $P_{\text {оп }}=p_{5}=6 . .18 \mathrm{MПа;} \mathrm{давление}$ за паровой турбиной $P_{2 П}=p_{6}=0,05 \ldots 0.3 \mathrm{MПа}$.

Для ОЦР было выбрано ОРТ, имеющее наилучшие термодинамические и экологические характеристики. С учетом проведенного в разделе 1 анализа выбраны OPT: pentane, butane, R365mfc, RC318, R236ea, R236fa, R123, R245са и R245fa.

C помощью программы проведены расчеты при $P_{\text {оп }}=18 \mathrm{MПа;} P_{2 \Pi}=0,2 \mathrm{MПа;} \mathrm{температуре} \mathrm{уходящих}$ газов $100{ }^{\circ} \mathrm{C}$, с изменением температуры конденсации ОРТ в диапазоне $-20 \ldots 20{ }^{\circ} \mathrm{C}$. Полученные в результате расчета зависимости КПД ПГУ брутто и нетто от температуры конденсации ОРТ приведены на рис. 3 . На рис. 4 приведена $t-Q$ диаграмма зависимости температуры уходящих газов, ОРТ, воды и пара от тепловой нагрузки поверхностей нагрева КУ, рассчитанная при тех же параметрах и температуре конденсации ОРТ $15{ }^{\circ} \mathrm{C}$.

На рис. 3 видим, что для всех ОРТ при изменении температуры конденсации КПД брутто изменяется линейно и, в зависимости от вида ОРТ, в узком диапазоне. При этом наилучшими являются pentane и RC318. КПД нетто имеет существенный разброс в зависимости от вида ОРТ, что связано с влиянием вязкости и плотности рабочих тел на работу сжатия в насосах. Наилучшими по КПД нетто являются pentane и R365mfc, при этом RC318 оказался на последнем месте. В связи с тем, что pentane является горючим и в определенном соотношении с воздухом может быть взрывоопасным, для дальнейших исследований выбран фреон R365mfc. Из проведенного расчета следует, что выбор ОРТ надо производить по КПД нетто с учетом затрат энергии на собственные нужды.

Из рис. 4 следует, что без подогрева ОРТ в ГПОРТ температура уходящих газов будет $192{ }^{\circ} \mathrm{C}$, таким образом ГПОРТ позволяет снизить температуру уходящих газов до $100{ }^{\circ} \mathrm{C}$ и повысить КПД КУ с 72,0 до $86,5 \%$, а также повысить температура OРТ с 60 до $92{ }^{\circ} \mathrm{C}$ перед ИОРТ, что увеличивает расход ОРТ и повышение мощности ТОРТ.

Для оценки влияния параметров водяного пара на КПД ПГУ проведены расчеты с изменением давления перед паровой турбиной $P_{\text {оп }}=p_{5}$ в диапазоне $6 . .18$ МПа и давления за турбиной $P_{2 п}$ в диапазоне 0,05...0,3 МПа. Результаты приведены на рис. 5, 6, где РП обозначает регенеративный подогрев ОРТ перед ГПОРТ КУ, а РЦ подогрев рециркуляцией. 


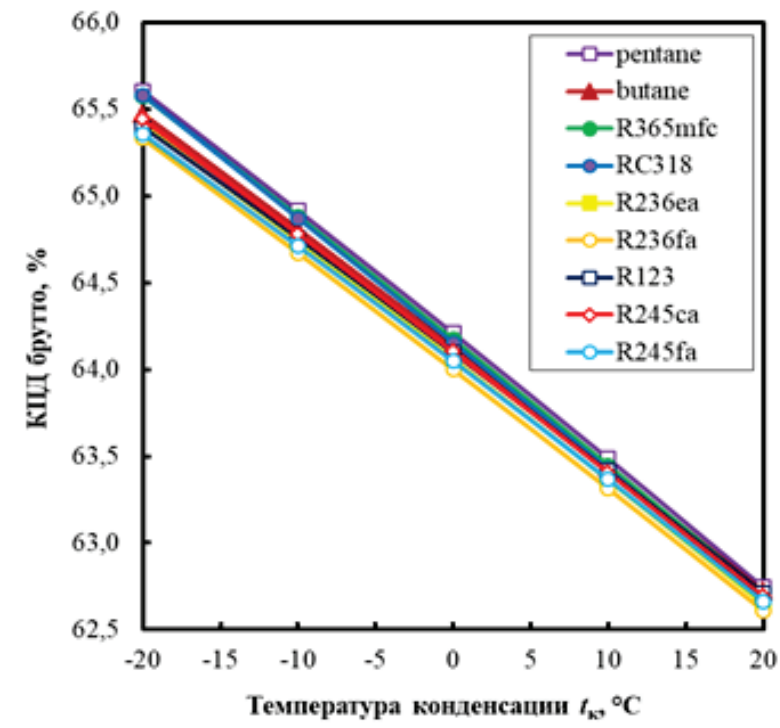

$a / a$

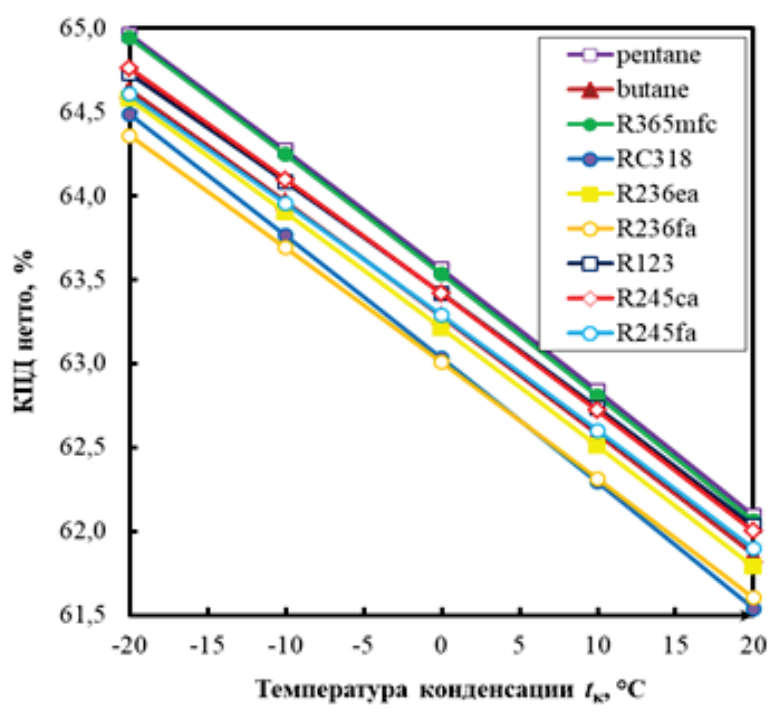

$b / b$

Puc. 3 а) КПД брутто; b) КПД нетто

Fig. 3. a) Gross efficiency; b) Net efficiency

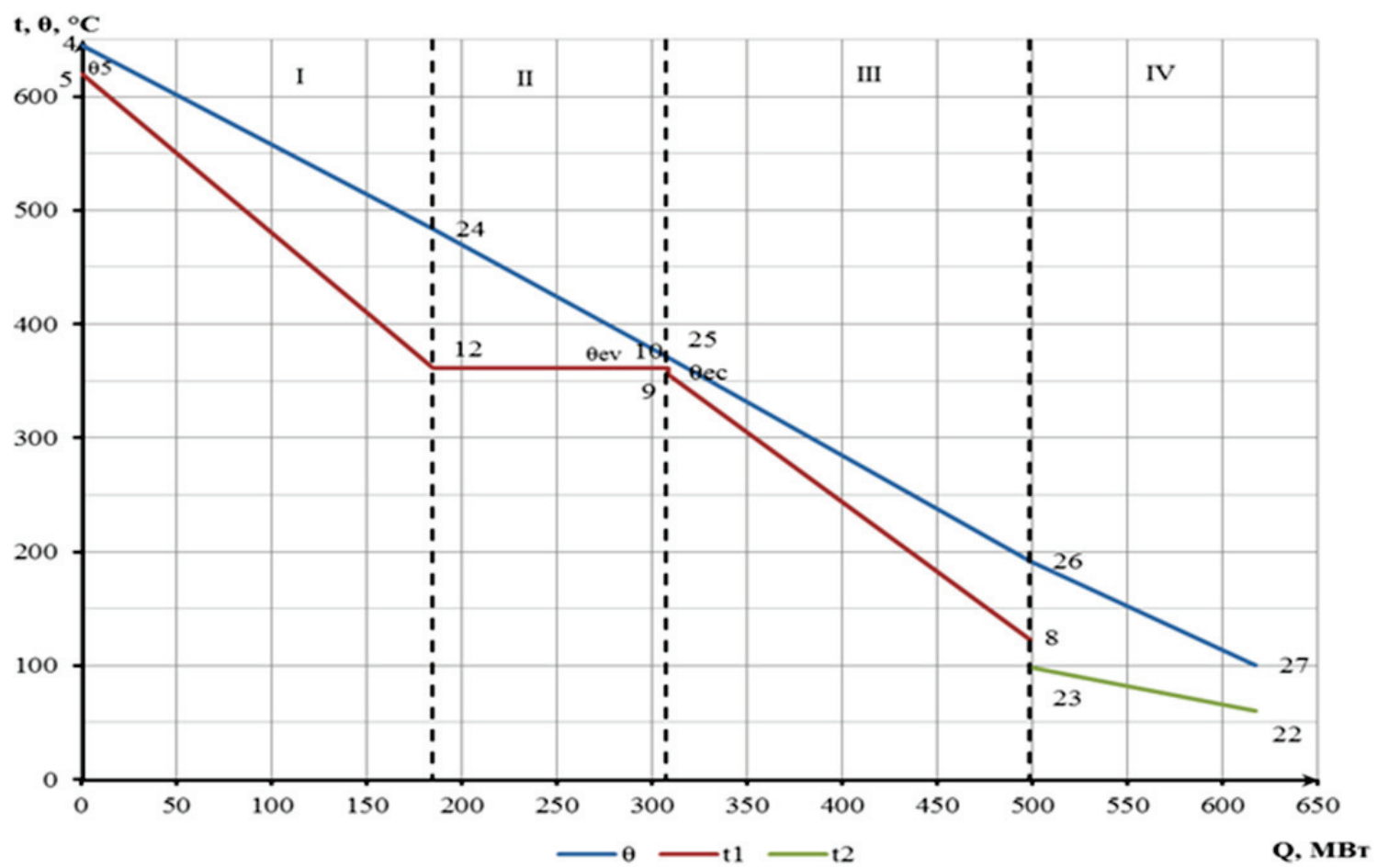

Pис. 4. t-Q-диаграмла КУ: $\theta$ - телпература выхлопных газов, $t_{1}$ - телпература воды и водяного пара, $t_{2}-$ температура ОРТ; числа соответствуют точкам на рис. 1; I - область пароперегревателя, II - область испарителя, III - область экономайзера, IV- область ГПОРТ

Fig. 4. $t$-Q-diagram of heat recovery steam generator (HRSG): $\theta$-exhaust gas temperature of the Gas turbine unit (GTU), $t_{1}-$ water vapor temperature of the high pressure circuit, $t_{2}$ - low pressure circuit OWF temperature; the numbers denote the points shown in Fig. 1 ; $I$ - superheater, II - evaporator, III - economizer, IV-GH OWF

На рис. 5 видим, что рост давления пара перед паровой турбиной линейно повышает КПД ПГУ, при этом рост давления на 2 МПа увеличивает КПД брутто на 0,25\%, а КПД нетто - на 0,3\% . Peгенеративный подогрев ОРТ перед КУ увеличивает
КПД брутто и нетто на 0,4 \% по сравнению с подогревом рециркуляцией.

Из рис. 6 следует, что в зависимости от давления за паровой турбиной $P_{2 \pi}$ имеется оптимум КПД ПГУ. Оптимальное давление $P_{2 \pi}$ зависит от 


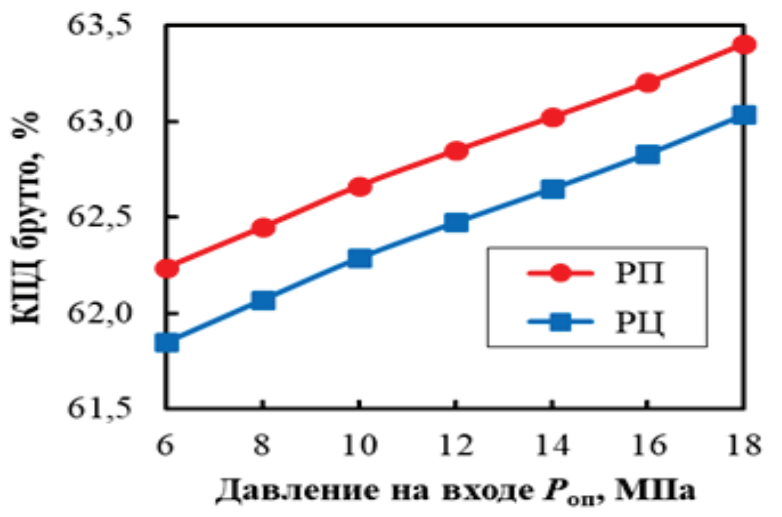

$a / a$

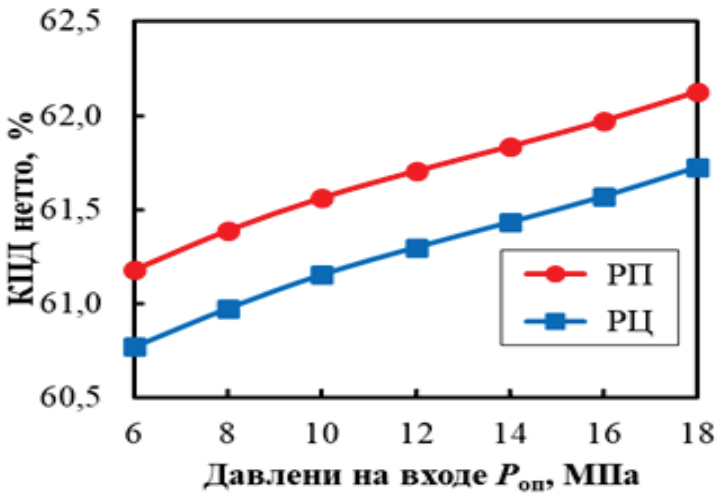

$\sigma / b$

Puc. 5. Зависимость КПД брутто (а) и нетто (б) ПГУ от давления $P_{\text {оп }}$

Fig. 5. Characteristic curve of gross ( $a$ ) and net (b) efficiency of CCGT from pressure $P_{0 \mathrm{Ws}}$

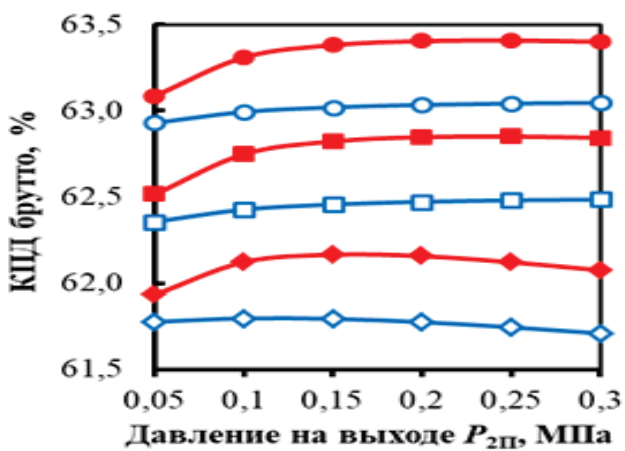

a/a

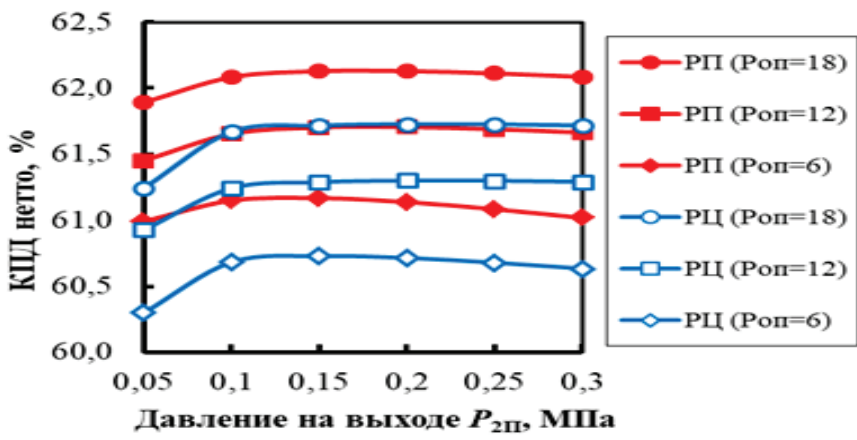

$\sigma / b$

Puc. 6. Зависимость КПД ПГУ брутто (а) и нетто (б) от $P_{2 \Pi}$ и $P_{\text {оп }}, M \Pi а$

Fig. 6. Characteristic curve of the gross (a) and net (b) efficiency of the CCGT from the pressure $P_{2 \mathrm{ws}}$ and $P_{0 \mathrm{ws}}, M P a$

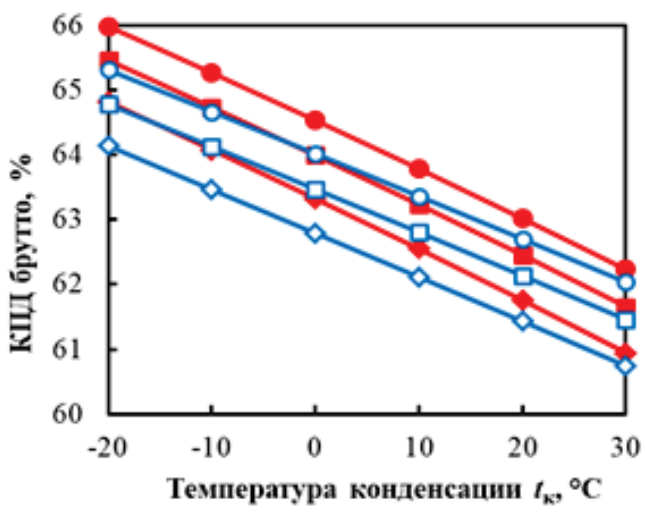

$a / a$

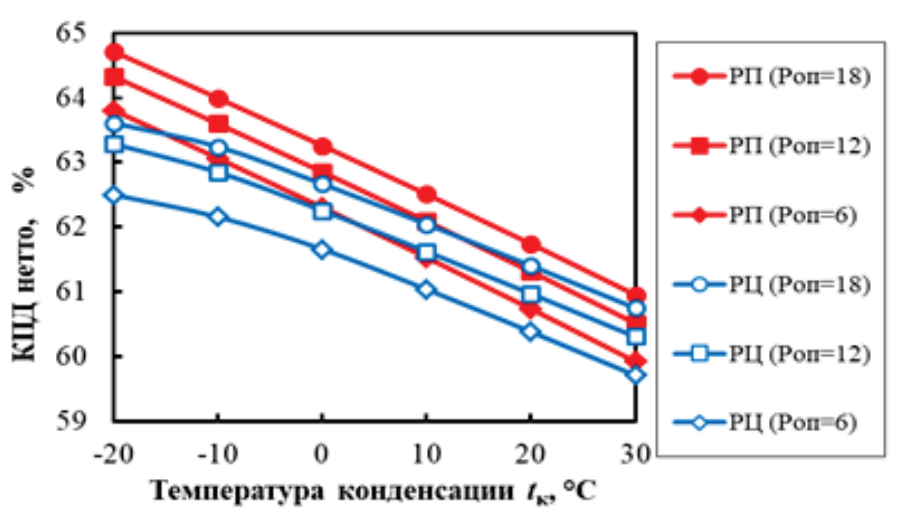

$\sigma / b$

Puc. 7. Зависимость КПд ПГУ брутто (а) и нетто (б) от температуры конденсации $t_{\mathrm{K}} и P_{\text {оп }}$

Fig. 7. Characteristic curve of the gross $(a)$ and net $(b)$ efficiency of the CCGT from condensation temperature $t_{\mathrm{K}}$ and $P_{0 \mathrm{ws}}$

способа подогрева ОРТ перед КУ (РП или РЦ) и давления пара $P_{\text {оп }}$ При этом их влияние более выражено для КПД ПГУ нетто. Так, при подогреве ОРТ перед КУ рециркуляцией максимум КПД ПГУ брутто и нетто слабовыраженный, имеется только сильное падение КПД ПГУ нетто при давлении $P_{2 п}$ ниже 0,1 МПа. При регенеративном подогреве ОРТ перед КУ в зависимости от давле-

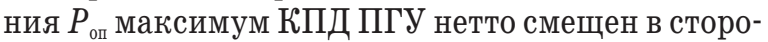
ну меньших давлений $P_{2 п}$. Так, для КПД ПГУ брутто при $P_{\text {ог }}=6 \mathrm{MПа} \mathrm{максимум} \mathrm{при}$ $P_{2 \Pi}=0,15 \ldots 0,2$ МПа, а для $P_{\text {оп }}=12$ и 18 МПа максимум при $P_{2 П}=0,2 \ldots 0,3$ МПа. Для КПД ПГУ нетто максимум более выраженный и смещен в сторону 
меньших $P_{2 \pi}$. Так, при $P_{\text {оп }}=6$ МПа максимум при $P_{2 \Pi}=0,1 \ldots 0,15 \mathrm{MПа,} \mathrm{а} \mathrm{для} P_{\text {оп }}=12$ и 18 МПа максимум при $P_{2 \Pi}=0,15 \ldots 0,2$ МПа.

На рис. 7 видим, что снижение температуры конденсации $t_{\mathrm{K}}$ линейно повышает КПД ПГУ брутто. При подогреве ОРТ перед КУ рециркуляцией темп роста КПД ниже, что связано с ростом расхода ОРТ по линии рециркуляции и уменьшением его расхода на турбину. Особенно влияние рециркуляции сказывается на КПД ПГУ нетто, из-за увеличения затрат мощности на насосы рециркуляции при низких $t_{\mathrm{K}}$ видим изгиб кривых КПД вниз. При регенеративном подогреве ОРТ КПД нетто изменяется линейно, при этом снижение $t_{\mathrm{K}}$ на $10{ }^{\circ} \mathrm{C}$ ведет к росту КПД ПГУ брутто и нетто на $0,76 \%$.

Проведенные расчеты показывают, что для увеличения КПД ПГУ необходимо увеличение давления пара перед паровой турбиной, снижение температуры конденсации ОРТ и оптимизация давления за паровой турбиной.

\section{Выводы}

1. Разработана оригинальная схема парогазовой установки утилизационного типа с циклами на трех рабочих телах, где верхний цикл Брайтона работает на продуктах сгорания природного газа, средний цикл Ренкина работает на воде и водяном паре, нижний - Органический цикл Ренкина - работает на органическом рабочем теле с конденсацией его в воздушном конденса-

\section{СПИСОК ЛИТЕРАТУРЫ}

1. Combined-Cycle Gas \& Steam Turbine Power Plants / R. Kehlhofer, F. Hannemann, F. Stirnimann, B. Rukes. Tulsa, Oklahoma, USA: PennWell Corporation, 2009. - 434 c.

2. Трухний А.Д. Парогазовые установки электростанций. - М.: ИД МЭИ, 2013. - 648 с.

3. Цанев С.В., Буров В.Д., Ремезов А.Н. Газотурбинные и парогазовые установки тепловых электростанций. - М.: ИД МЭИ, 2002. $-584 \mathrm{c}$

4. Ольховский Г.Г. Перспективные газотурбинные и парогазовые установки для энергетики (обзор) // Теплоэнергетика. 2013. - № 2. - C. 3-12.

5. Multi-objective optimisation and fast decision-making method for working fluid selection in organic Rankine cycle with lowtemperature waste heat source in industry / Xu Zhang, Hao Bai, Xiancong Zhao, Ali Diabat, Jian Zhang, Huanmei Yuan, Zefei Zhang // Energy Conversion and Management. - 2018. V. 172 . - P. 200-211.

6. Design optimization of ORC systems for waste heat recovery on board a LNG carrier / M. Soffiato, Ch.A. Frangopoulos, G. Manente, S. Rech, A. Lazzaretto // Energy Conversion and Management. - 2015. - V. 92. - P. 523-534.

7. A multi-criteria approach for the optimal selection of working fluid and design parameters in Organic Rankine Cycle systems / A. Toffolo, A. Lazzaretto, G. Manente, M. Paci // Applied Energy. 2014. - V. 121. - P. 219-251.

8. Yang M., Yeh R. Analyzing the optimization of an organic Rankine cycle system for recovering waste heat from a large marine engine containing a cooling water system // Energy Converse Manage. 2014. - V. 88. - P. 999-1010. торе. Разработана математическая модель и программа расчета предложенной схемы.

2. Для органического цикла Ренкина определено наиболее эффективное органическое рабочее тело - фреон R365mfc.

3. Проведен параметрический анализ влияния основных параметров циклов Ренкина на КПД брутто и нетто парогазовой установки при подогреве ОРТ перед КУ с помощью регенеративного подогрева в смешивающем подогревателе паром из отбора турбины ОРТ и рециркуляцией OPТ через газовый подогреватель ОРТ. Определено, что регенеративный подогрев более эффективен, чем рециркуляция.

4. Выявлено, что рост давления пара перед паровой турбиной линейно повышает КПД ПГУ, при этом рост давления на 2 МПа увеличивает КПД брутто на 0,25\%, а КПД нетто - на 0,3\% .

5. Определено, что в зависимости от давления за паровой турбиной $P_{2 \pi}$ имеется оптимум КПД ПГУ. Так для КПД ПГУ брутто при $P_{\text {оп }}=6$ МПа максимум находится в интервале $P_{2 \Pi}=0,15 . .0,2 \mathrm{MПа}$, а для $P_{\text {оп }}=12$ и $18 \mathrm{MПа} \mathrm{максимум} \mathrm{в} \mathrm{интервале}$ $P_{2 \Pi}=0,2 . . .0,3$ МПа. Для КПД ПГУ нетто максимум смещен в сторону меньших $P_{2 п}$. Так, при $P_{\text {оп }}=6 \mathrm{MПа}$ максимум в интервале $P_{2 \Pi}=0,1 . .0,15 \mathrm{MПа}$, а для $P_{\text {оп }}=12$ и $18 \mathrm{MПа} \mathrm{максимум} \mathrm{в} \mathrm{интервале}$ $P_{2 \Pi}=0,15 \ldots 0,2 \mathrm{M \Pi l}$.

6. Выявлено, что снижение температуры конденсации ОРТ на $10{ }^{\circ} \mathrm{C}$ ведет к росту КПД ПГУ брутто и нетто на $0,76 \%$.

9. How to quantitatively describe the role of the pure working fluids in subcritical organic Rankine cycle: a limitation on efficiency / Weicong Xu, Shuai Deng, Li Zhao, Wen Su, Ying Zhang, Shuangjun Li, Minglu Ma // Energy Conversion and Management. 2018. - V. 172. - P. 316-327.

10. Working Fluids for Low-Temperature Organic Rankinee Cycles / B. Saleh, G. Koglbauer, M. Wendland, J. Fischer // Energy. 2007. - V. 32. - P. 1210-1221.

11. Braimakis K., Karellas S. Exergetic optimization of double stage Organic Rankine Cycle (ORC) // Energy. - 2018. - V. 149. P. 296-313.

12. Cao Y., Rattner A.S., Dai Y. Thermoeconomic analysis of a gas turbine and cascaded $\mathrm{CO}_{2}$ combined cycle using thermal oil as an intermediate heat-transfer fluid // Energy. - 2018. - V. 162. P. 1253-1268.

13. Parametric and working fluid analysis of a dual-loop organic Rankine cycle (DORC) used in engine waste heat recovery / G. Shu, L. Liu, H. Tian, H. Wei, G. Yu // Applied Energy. - 2014. V. 113. - P. 1188-1198.

14. Thermoeconomic analysis and multiobjective optimization of a combined gas turbine, steam, and organic Rankine cycle / A. Mohammadi, M. Ashouri, M.H. Ahmadi, M. Sadeghzadeh, T. Ming // Energy Science and Engineering. - 2018. - V. 6. P. 506-522.

15. Galashov N.N., Tsybulsky A.S. Thermal Efficiency of Three-Cycle Utilization-Type Steam-Gas Units // Power Technology and Engineering. - 2015. - V. 48. - P. 459-463.

16. Галашов Н.Н., Цибульский С.А. Анализ эффективности парогазовых установок тринарного типа // Известия томского политехнического университета. - 2014. - Т. 325. - № 4. C. 33-38. 
17. Галашов Н.Н., Цибульский С.А. Анализ влияния основных параметров паротурбинного цикла на эффективность тринарных парогазовых установок // Известия Томского политехнического университета. - 2013. - Т. 323. - № 4. - С. 14-21.

18. Galashov N., Tsibulskiy S., Serova T. Analysis of the properties of working substances for the organic Rankine cycle based database "refprop» // Termophysical basis of energy technologies 2015: EPJ web of conferences. - Tomsk, - 2016. V. 110 (01068). -6 p.
19. Lemmon E.W., Huber M.L., McLinden M.O. Reference fluid thermodynamic and transport properties-REFPROP. 2013. URL: https://www.nist.gov/programs-projects/reference-fluid-thermodynamic-and-transport-properties-database-refprop (дата обращения: 19.02.2019).

20. Параметры газовой турбины 9HA. 2018. URL: https://www.ge. com/power/gas/gas-turbines/9ha (дата обращения: 19.02.2019).

Поступила 27.03.2019 2.

\section{Информация об авторах}

Галашов Н.H., кандидат технических наук, доцент НОЦ И.Н. Бутакова инженерной школы энергетики Национального исследовательского Томского политехнического университета.

Цибульский C.A., ассистент НОЦ И.Н. Бутакова инженерной школы энергетики Национального исследовательского Томского политехнического университета. 
UDC 621.311.238; 621.311.22

\title{
PARAMETRIC ANALYSIS OF THE DIAGRAM OF THE COMBINED-CYCLE GAS TURBINE WITH A COMBINATION OF THREE CYCLES FOR IMPROVING EFFICIENCY WHEN OPERATING IN NORTHERN GAS PRODUCING AREAS
}

\author{
Nikolay N. Galashov', \\ gal@tpu.ru \\ Svyatoslav A. Tsibulskiy', \\ stzibulsky@tpu.ru \\ ${ }^{1}$ National Research Tomsk Polytechnic University,
30, Lenin avenue, Tomsk, 634050, Russia.
}

The relevance. Combined-cycle gas turbines are considered as one of the promising directions in development of thermal power plants operating on natural and synthesis gas. The interest in their introduction in Russia is caused by large reserves of natural gas, low capital investment and minimal emissions of harmful substances into the environment. It is known from thermodynamics that in order to achieve high cycle efficiency, it is necessary to have a high heat supply temperature and low heat removal temperature, and to ensure equipment operation with minimal internal losses, and to have a rational thermal scheme of equipment interconnection in a cycle. At the present stage, the maximum temperature of heat supply in the combustion chamber of a gas turbine installation with existing structural materials and methods for cooling turbine elements has reached $1600{ }^{\circ} \mathrm{C}$, and heat removal temperature in the condenser during the operation of the Rankine cycle on water cannot be lower than $15{ }^{\circ} \mathrm{C}$. Under these conditions, the electric efficiency of $63 \%$ is achieved at the most advanced three-loop combined-cycle gas turbine with intermediate superheating of steam. For the Rankine cycle when working on water, the condensation temperature of the steam should be above $0^{\circ} \mathrm{C}$ according to the freezing condition. For a combined-cycle plant, when operating in conditions of low average annual ambient temperatures, which is typical for Russia and especially remote northern gas production areas, heat can be removed in the Rankine cycle well below $0{ }^{\circ} \mathrm{C}$, but this can be done reliably only by using aircooled condensers, if an organic working body is used as a working body in the Rankine cycle. The disadvantage of modern organic working fluid is the low limiting temperature of their thermal decomposition, which is usually below $300 \ldots 400^{\circ} \mathrm{C}$.

Subject of the research is combined-cycle plants with cycles on three working bodies, where the upper cycle of a gas turbine unit operates on gas combustion products, the middle cycle of a steam turbine unit operates on water and steam in the temperature range of $100 . .650^{\circ} \mathrm{C}$, and the lower cycle - Organic Rankine cycle operates on organic working fluid in the range of temperatures $-30 \ldots 200^{\circ} \mathrm{C}$. The aim of the study is the choice of a rational technological diagram of a combined-cycle plants using cycles on three working bodies and an air condenser to enable reliable heat removal from the organic working fluid at temperature below $0{ }^{\circ} \mathrm{C}$ and to determine the optimal parameters of the cycles.

Methods. Complex heat and power systems, including steam and gas installations, are characterized by a variety of processes occurring in their elements. Such installations can be effectively investigated only with the help of mathematical modeling and optimization methods. When conducting research the authors have applied a systematic approach, methods of energy balances and the calculation of thermodynamic and thermophysical property of working bodies using modern certified programs.

Results. The authors developed the original diagram of a combined-cycle gas turbine unit with cycles on three working bodies. In this diagram, the Brighton upper cycle operates on combustion products of natural gas, the average Rankine cycle operates on water and water vapor, the lower - Organic Rankine cycle operates on organic working fluid with condensation in an air condenser. The mathemati$\mathrm{cal}$ model and a program for calculating the proposed scheme was developed. The authors carried out the parametric analysis of the cycles main parameters influence on the efficiency and power of the combine cycle gas turbine and determined the most effective organic working fluid for the lower Rankine cycle.

\section{Key words:}

Combined-cycle gas turbine, organic working bodies, Organic Rankine cycle, air condenser, math modeling.

\section{REFERENCES}

1. Kehlhofer R., Hannemann F., Stirnimann F., Rukes B. Combinet Cycle Gas \& Steam Turbine Power Plants. Tulsa, Oklahoma, USA, 2009, PennWell Corporation. 434 p.

2. Trukhny A.D. Parogazovye ustanovki elektrostantsy [Steam-gas installations of power plants]. Moscow, MEI Publ. House, 2013. $648 \mathrm{p}$.

3. Tsanev S.V., Burov V.D., Remezov A.N. Gazoturbinnye i paroga zovye ustanovki teplovykh stantsy [Gas turbine and steam-gas installations of thermal power plants]. Moscow, MEI Publ. House, $2002.584 \mathrm{p}$

4. Olkhovsky G.G. Perspektivnye gazoturbinnye i parogazovye ustanovki dlya energetiki (obzor). Teployenergetika, 2013, no. 2, pp. 3-12. In Rus.

5. Xu Zhang, Hao Bai, Xiancong Zhao, Ali Diabat, Jian Zhang, Huanmei Yuan, Zefei Zhang. Multi-objective optimisation and fast decision-making method for working fluid selection in orga- nic Rankine cycle with low-temperature waste heat source in industry. Energy Conversion and Management, 2018, vol. 172, pp. 200-211.

6. Soffiato M., Frangopoulos Ch.A., Manente G., Rech S., Lazzaretto A. Design optimization of ORC systems for waste heat recovery on board a LNG carrier. Energy Conversion and Management, 2015 , vol. 92 , pp. 523-534.

7. Toffolo A., Lazzaretto A., Manente G., Paci M. A multi-criteria approach for the optimal selection of working fluid and design parameters in Organic Rankine Cycle systems. Applied Energy, 2014, vol. 121, pp. 219-251.

8. Yang M., Yeh R. Analyzing the optimization of an organic Rankine cycle system for recovering waste heat from a large marine engine containing a cooling water system. Energy Converse Manage, 2014, vol. 88, pp. 999-1010.

9. Weicong Xu, Shuai Deng, Li Zhao, Wen Su, Ying Zhang, Shuangjun Li, Minglu Ma. How to quantitatively describe the role of the 
pure working fluids in subcritical organic Rankine cycle: A limitation on efficiency. Energy Conversion and Management, 2018, vol. 172, pp. 316-327.

10. Saleh B., Koglbauer G., Wendland M., Fischer J. Working Fluids for Low-Temperature Organic Rankinee Cycles. Energy, 2007, vol. 32, pp. 1210-1221.

11. Braimakis K., Karellas S. Exergetic optimization of double stage Organic Rankine Cycle (ORC). Energy, 2018, vol. 149, pp. 296-313.

12. Cao Y., Rattner A.S., Dai Y. Thermoeconomic analysis of a gas turbine and cascaded $\mathrm{CO}_{2}$ combined cycle using thermal oil as an intermediate heat-transfer fluid. Energy, 2018, vol. 162, pp. 1253-1268.

13. Shu G., Liu L., Tian H., Wei H., Yu G. Parametric and working fluid analysis of a dual-loop organic Rankine cycle (DORC) used in engine waste heat recovery. Applied Energy, 2014, vol. 113, pp. 1188-1198.

14. Mohammadi A., Ashouri M., Ahmadi M.H., Sadeghzadeh M., Ming T. Thermoeconomic analysis and multiobjective optimization of a combined gas turbine, steam, and organic Rankine cycle. Energy Science and Engineering, 2018, vol. 6, pp. 506-522.

15. Galashov N.N., Tsybulsky S.A. Thermal Efficiency of Three-Cycle Utilization-Type Steam-Gas Units. Power Technology and Engineering, 2015, vol. 48, Iss. 6, pp. 459-463.

\section{Information about the authors}

Nikolay N. Galashov, Cand. Sc., associate professor, National Research Tomsk Polytechnic University.

Svyatoslav A. Tsibulskiy, assistant, National Research Tomsk Polytechnic University.
16. Galashov N.N., Tsybulsky S.A. Analysis of the efficiency of combined-cycle installations of the trinar type. Bulletin of the Tomsk Polytechnic University, 2014, vol. 325, no. 4, pp. 33-38. In Rus.

17. Galashov N.N., Tsibulsky S.A. Analysis of the influence of the main parameters of the steam-turbine cycle on the efficiency of trinar steam-gas installations. Bulletin of the Tomsk Polytechnic University, 2013, vol. 323, no. 4, pp. 14-21. In Rus.

18. Galashov N., Tsibulskiy S., Serova T. Analysis of the properties of working substances for the organic Rankine cycle based database «Refprop». EPJ web of conferences. Termophysical basis of energy technologies 2015. Tomsk, 2016. Vol. 110 (01068), 6 p.

19. Lemmon E.W., Huber M.L., McLinden M.O. Reference fluid thermodynamic and transport properties-REFPROP. 2013. Available at: https://www.nist.gov/programs-projects/reference-fluidthermodynamic-and-transport-properties-database-refprop (accessed 19 February 2019).

20. Parametry gazovoy turbiny $9 H A$ [Gas turbine 9HA parameters]. 2018. Available at: https://www.ge.com/power/gas/gas-turbines/9ha (accessed 19 February 2019).

Received: 27 March 2019. 